\title{
Curcumin: an adjuvant therapeutic remedy for liver cancer
}

\author{
Shilpa Sharma, Anshul Tanwar, Devendra K. Gupta \\ Department of Pediatric Surgery, All India Institute of Medical Sciences, New Delhi 110029, India.
}

\begin{abstract}
The molecular signalling pathways for hepatocellular carcinoma and hepatoblastoma have been extensively studied. The treatment of these highly vascular tumors mainly revolves around chemotherapy and surgery. Yet there is a high associated morbidity and mortality due to advanced stages, adverse effects owing to chemotherapy and recurrence. The role of Curcumin as an adjuvant remedy is explored in this article. Curcumin stimulates apoptosis of cancer cells, acts as anti-proliferative agent, has anti-angiogenic action, prevents tumor invasiveness and metastasis and prevents recurrence. It also has been proven to decrease the adverse effects of chemotherapeutic agents and has a synergistic anticancer action. It acts at the molecular level and affects the various metabolic pathways involved in tumorigenesis. It also promotes healing and has antiinflammatory, anti-oxidant and anti-infective action. This natural phytocompounds has immense anti-cancer potential and holds future promise as an adjuvant remedy to treat liver cancer.
\end{abstract}

Key words: Curcumin; hepatoblastoma; hepatocellular carcinoma; diferuloylmethane

\section{Address for correspondence:}

Dr. Shilpa Sharma, Department of Pediatric Surgery, All India Institute of Medical Sciences, New Delhi 110029, India. E-mail: drshilpas@ gmail.com.

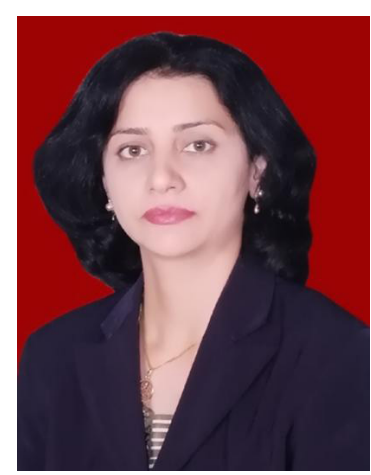

Dr. Shilpa Sharma is a faculty (Asst. Professor) of Pediatric Surgery at All India Institute of Medical Sciences, New Delhi. Her qualifications include MBBS - 1996, MS Gen Surgery -1999, MCh and DNB - Pediatric Surgery - 2004. She is involved in the surgical care of children since last 15 years with research interests in stem cells. She has also done PhD on stem cells from All India Institute of Medical Sciences, New Delhi in 2010. Her notable awards include Dr. Shoor Vir Singh Prize, UC Chakravorty Research Award, Shanti Talwar Fellowship, Swapan Datta Research Award, Purushotom Upadhyay Research Award for the best paper published in 2010, James Lister fellowship of the British Association of Pediatric Surgeons in 2012 and the WOFAPS scholarship from the World Federation of Association of Pediatric Surgeons 2014 under which she was a fellow at GOS Hospital for Children at London, UK. She has published 56 research papers and 80 book chapters, delivered more than 60 guest lectures and presented more than 110 papers at various national and international conferences. She has served as an Editorial Assistant for Journal of Indian Association of Pediatric Surgeons and is presently an Editorial Consultant for two International journals apart from being a reviewer of many peer reviewed journals. She has served as Secretary of the Delhi chapter of Indian Association of Pediatric Surgeons from 2011-2014 and is currently the Secretary of the Research Section of the Indian Association of Pediatric Surgeons since 2011.

Received: 25-10-2015, Accepted: 19-01-2016

\section{INTRODUCTION}

Primary liver cancer characterised by active neovascularization is among the most common lethal cancers worldwide and can occur at any age. Hepatocellular carcinoma (HCC) occurs in older children and adults and has a high prevalence in developing Asian

\begin{tabular}{|l|c|}
\hline \multicolumn{3}{|c|}{ Access this article online } \\
\hline \multirow{2}{*}{ Website: } & Quick Response Code \\
\cline { 2 - 2 } http://www.hrjournal.net/ & \\
\hline &
\end{tabular}

and African countries. In children under five years of age, hepatoblastoma (HB) accounts for more than $90 \%$ of primary hepatic malignant tumors and HCC for $12.5 \% .^{[1]}$

With recent advances in diagnostic technology, the incidence of HCC and HB has been increasing in the past decades, especially in Europe and North America. ${ }^{[2]}$ Risk

This is an open access article distributed under the terms of the Creative Commons Attribution-NonCommercial-ShareAlike 3.0 License, which allows others to remix, tweak, and build upon the work non-commercially, as long as the author is credited and the new creations are licensed under the identical terms.

For reprints contact: service@oaepublish.com

How to cite this article: Sharma S, Tanwar A, Gupta DK. Curcumin: an adjuvant therapeutic remedy for liver cancer. Hepatoma Res 2016;2:6270. 
factors for HCC include cirrhosis, hepatocarcinogenic like aflatoxins and nitrosamines, dietary and environmental carcinogens by generation of reactive oxygen species (ROS) and infections like hepatitis B and C viruses. ${ }^{[2]}$

The current management of liver tumors is not satisfactory. Chemotherapy, surgery, and radiofrequency ablation are all directed at reducing the tumor bulk. However, in the majority of cases, tumor recurrence and relapse occurs on completion of therapy. Also, liver cancer is diagnosed at an advanced stage quite frequently; hence the available chemotherapy regimens fail to offer a complete cure. Even if chemotherapy has been instituted timely, the available chemotherapeutic agents are reported to show severe adverse effects. Angiogenesis plays a significant role in human HCC tumor progression and recent studies are focussing on anti-angiogenic agents targeting specific tumor vasculature. ${ }^{[3]}$

In this regard, discovery of natural phytocompounds having anti-tumor and anti-angiogenic activities could have greater clinical significance as they do not affect physiology and survival of normal cells. Many phytochemicals have proven anti-tumor action including catechins, quercetin in apples and onions, resveratorl in grapes, red wine, peanuts, and ellagic acid in pomegranates. ${ }^{[4]}$ This review describes firstly the molecular pathology of liver cancers and then summaries the evidence based literature that describes the various proven mechanism demonstrating the anti-tumor potential of curcumin in turmeric (Curcuma longa) and thus exploring its role as an adjuvant therapeutic remedy for liver cancer.

\section{CURCUMIN}

Curcumin is the active phytoconstituent of turmeric. It has been widely used as a therapeutic medicine in Indian traditional medicine. Of late, scientists all over the world have recognized its therapeutic potential as an antiinflammatory, anti-oxidant and anti-cancer agent. ${ }^{[8-11]}$ Curcumin inhibits lipid peroxidation and maintains the normal concentration of intracellular antioxidant enzymes like catalase, glutathione peroxidase and superoxide dismutase and scavenges reactive oxygen species effectively. ${ }^{[12,13]}$

\section{TUMORIGENESIS AND MOLECULAR BIOLOGY OF LIVER CANCER}

Tumorigenesis of liver cancer is a complex process. The recognition of tumor stem cells and their molecular signaling has opened new pathways for therapeutic strategies. The liver has great potential to regenerate after the loss of hepatic tissue which depends on proliferation of existing mature hepatocytes.

Growth factors like hepatocyte growth factor, epidermal growth factor and transforming growth factor (TGF)-alpha control normal hepatic regeneration via DNA synthesis stimulation. TGF- $\beta$ and activin serve as negative feedback mechanisms and regulate the end point of the hepatocyte proliferation. This termination is regulated by the ratio of liver to body mass thus providing a check on the extent of liver regeneration. ${ }^{[14]}$

Liver stem cells are proposed to be from dual origins, intrahepatic with short-term proliferative capacity present within the canals of Herring and interlobular bile ducts and extrahepatic derived from bone marrow and peripheral blood cells with long-term proliferation capacity. ${ }^{[15]}$

\section{MOLECULAR SIGNALING PATHWAYS IN LIVER CANCER}

Liver cancer stem cells have many signals to maintain self-renewal and pluripotency including EpCAM, Wnt/ $\beta$ catenin pathway, Sonic Hedgehog pathway, and Notch pathway, which play a decisive role in the regulation and maintenance of stemness and in tumor formation. Tumorigenesis results from uncontrolled activation of these pathways. Wnt pathway proteins regulate the cellular fate and self-renewal of stem cells. ${ }^{[16]}$ The Notch pathway is involved in cellular differentiation, fate of the cell, cellular proliferation, apoptosis, and cell adhesion. Notch signaling in the liver is involved in cholangiocyte differentiation. ${ }^{[17]}$

\section{HEPATOCELLULAR CARCINOMA}

\section{EpCAM signaling pathway}

EpCAM consists of a large extracellular, a single transmembrane and a short intracellular domain. There is a cross-talk between EpCAM signaling and the Wnt pathway. ${ }^{[18,19]}$

\section{Wnt/ $\beta$-catenin signaling pathway}

The $\mathrm{Wnt} / \beta$-catenin pathway is essential for development, growth, survival, regeneration, and self-renewal. ${ }^{[20]}$ Disruption of Wnt/ $\beta$-catenin signaling by mutational and non-mutational events is associated with many cancers, including HCC. Disrupted Wnt/ $\beta$-catenin signaling pathway has been reported in around one third of all HCCs. ${ }^{[21]}$ However, the point at which cross-talk occurs in the signaling cascades of Wnt/Frizzled and EpCAM remains unknown.

\section{SALL4 signaling pathway}

As an oncofetal gene, SALL4 is expressed at high levels in fetal-liver progenitor cells but not in adult hepatocytes, and it has an important role in hepatic cell lineage commitment. ${ }^{[22,23]}$

\section{TGF- $\beta$ family}

The TGF- $\beta$ family controls cellular differentiation and proliferation in both cancer stem cells and cancer cells. Impaired TGF- $\beta$ signaling through the activation of 
interleukin-6 in hepatic stem/progenitor cells can cause HCC. ${ }^{[24]}$ TGF- $\beta$ inhibits cell proliferation and promotes tumor cell invasion. Many studies have reported a reduction of TGF- $\beta$ receptors in up to $70 \%$ of HCCs that also correlated with metastasis within the liver. On the other hand, high TGF- $\beta$ levels have been correlated with advanced clinical stages of HCC. This twofold role of TGF- $\beta$ signaling in HCC is explained by the tumor microenvironment and selective loss of TGF- $\beta$-induced antiproliferative pathway. Tumor cells that have selectively lost their growth-inhibitory response to TGF- $\beta$, but retain a functional TGF- $\beta$ signaling pathway may exhibit increased migration and invasive behaviour on TGF- $\beta$ stimulation. Cells with dysfunctional TGF- $\beta$ signaling have been reported to be cancer progenitor cells giving rise to HCC. ${ }^{[25]}$

\section{The Notch signaling pathway}

This plays an important role in stem cell self-renewal and differentiation. Notch signaling is important in liver embryogenesis, bile duct formation; angiogenesis and endothelial sprouting. However, other signaling pathways have a control on whether Notch functions as a tumor suppressor or oncogene. ${ }^{[26]}$ The increased expression of genes involved in this pathway has been shown in CD133positive liver cancer cells vs. CD133-negative cells. The activated intracellular form of Notch-3, and the Notch ligand Jagged, is highly expressed in HCC. Activation of
Notch-1 signaling increases the death receptor 5 (DR5) expression with augmentation of tumor necrosis factor (TNF)-related apoptosis-inducing ligand induced apoptosis in vitro and in vivo. ${ }^{\mid 27]}$

\section{Sonic Hedgehog pathway}

Activation of Hedgehog signalling is related to liver cancer. ${ }^{[28]}$ Up to $60 \%$ of human HCCs express Sonic Hedgehog. After specific blockade of the sonic Hedgehog pathway, concomitant down regulation of Gli-related target genes is observed. Furthermore, tumorigenic activation of SMO can mediate over expression of c-myc, a gene having an important pathogenic role in liver carcinogenesis.

\section{miRNAs}

miRNAs directly interact with specific messenger RNAs (mRNAs) through base pairing and inhibiting the expression of target genes. MiRNAs can undergo anomalous regulation during carcinogenesis, and can act as oncogenes or tumor suppressor genes. MiR-181 also regulates the $W n t / \beta$-catenin signaling pathway with a positive feedback loop within stem cells. This is used by cancer cells to self-propagate continuously, metastasize and develop drug resistance.

\section{HEPATOBLASTOMA}

The best characterized pathways in pathogenesis of $\mathrm{HB}$

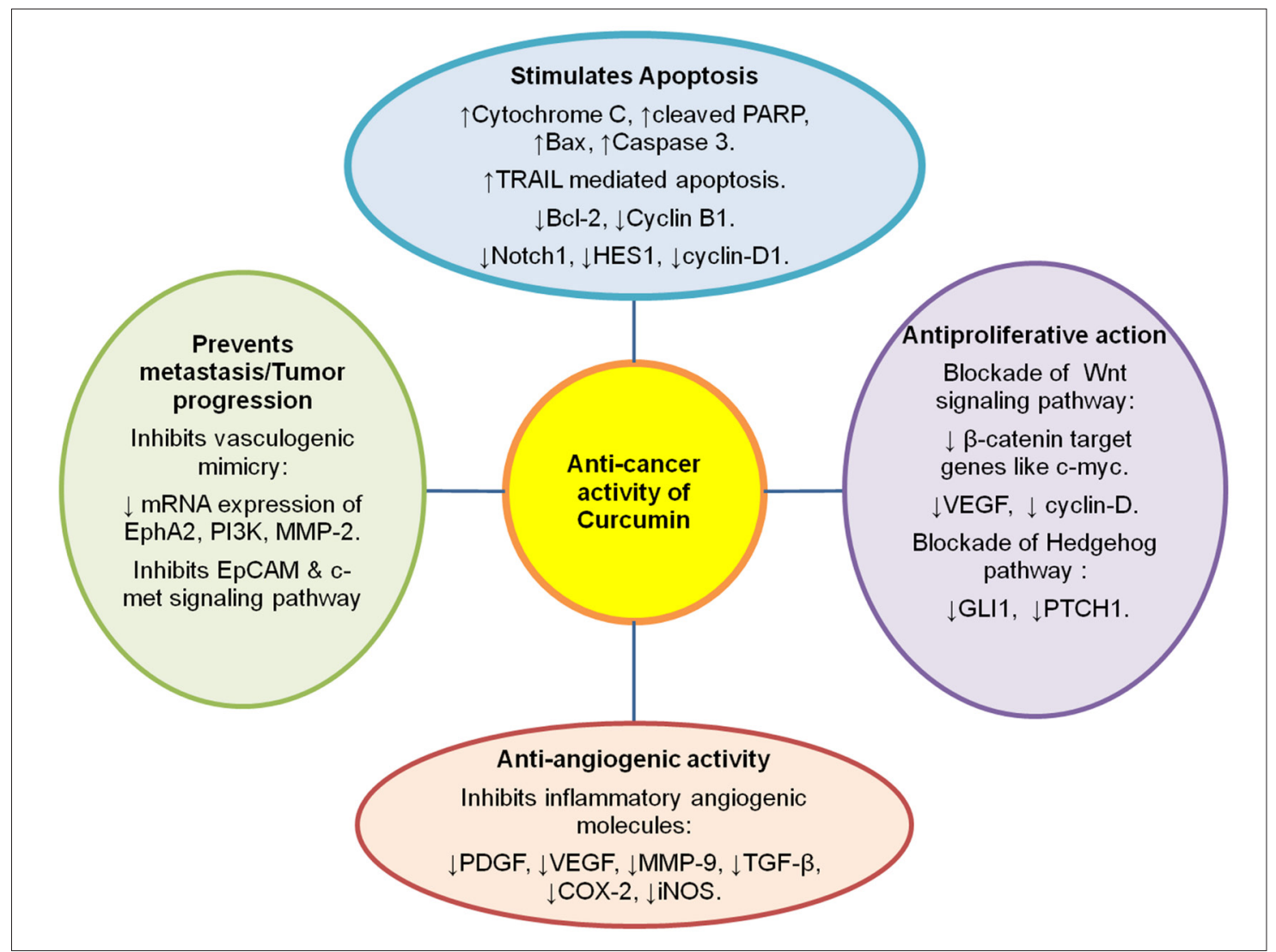

Figure 1: Flow chart depicting the various anti-cancer properties of curcumin. VEGF: vascular endothelial growth factor; MMP: matrix metalloproteinase; PDGF: platelet derived growth factor; TGF: transforming growth factor; COX: cyclooxygenase; iNOS: inducible nitric oxide synthase; EpCAM: epithelial cell adhesion molecule 
include the following.

\section{Canonical Wnt/beta-catenin signaling pathway}

Multiple Wnt/beta-catenin target genes are key regulators of cellular proliferation, anti-apoptosis and angiogenesis. These include c-myc, cyclin D1, FRA-1, matrix metalloproteinase-7, c-Jun, urokinase plasminogen activator receptor, immunoglobulin transcription factor 2 , endothelial growth factor receptor and vascular endothelial growth factor (VEGF) receptor. ${ }^{[29-31]}$ In the absence of Wnt ligand, the Wnt/beta-catenin signaling pathway is turned off and beta-catenin undergoes ubiquitin-mediated degradation..$^{[32]}$

Majority of HBs contain beta-catenin gene mutations that prevent beta-catenin from being degraded. ${ }^{[33]}$ As a result, beta-catenin accumulates aberrantly in the cytoplasm, and then translocates to the nucleus. Most HBs have cytoplasm and nuclear beta-catenin levels. ${ }^{[34]}$ Nuclear localization of beta-catenin is leads to uncontrolled hepatoblast proliferation. ${ }^{[35]}$ Beta-catenin has been considered as a highly sensitive tumor marker for $\mathrm{HB}$.

Some HBs without beta-catenin mutations may also display beta-catenin accumulation due to other aberrant components. About 65\% of sporadic HBs possess adenomatous polyposis coli APC gene alterations. ${ }^{[36]}$ In absence of beta-catenin mutations, HBs with over expression of a catalytic subunit of the enzyme telomerase, telomerase reverse transcriptase also demonstrate betacatenin accumulation. ${ }^{[37]}$ The Wnt/catenin signaling in $\mathrm{HB}$ is dependent on the liver and may contribute more to the genesis of the embryonal than the fetal component of $\mathrm{HB} .^{[38]}$

\section{Hepatocyte growth factor/c-met signaling pathway}

Hepatocyte growth factor (HGF), the natural ligand for c-met receptors $\mathrm{HGF} / \mathrm{c}$-met signaling also leads to aberrant beta-catenin accumulation in hepatoblasts. ${ }^{[34,39]}$ After binding to HGF, c-met undergoes autophosphorylation on tyrosine residues and further downstream signaling. Beta-catenin is a substrate for tyrosine kinase. Tyrosine phosphorylation of beta-catenin shields beta-catenin from serine/threonine phosphorylation and subsequent degradation, and leads to beta-catenin accumulation in the tumor cells. Though this process is independent of Wnt but the result is the same.

\section{Notch signaling pathway}

The Notch signaling plays a critical role in stem cell renewal, differentiation, angiogenesis and endothelial sprouting. It is relevant for both hepatocyte embryogenesis and cholangiocyte differentiation.

Deregulation of Notch signaling in $\mathrm{HB}$ has been documented. ${ }^{[40]}$ Notch activation is associated more with the subtype pure fetal HB. The role of Notch signaling in tumorigenesis is dependent on the cellular context. The crosstalk between Notch and Ras, a cell survival pathway, or the death receptor 5 , an apoptotic pathway, may decide whether Notch functions as an oncogene or a tumor suppressor, respectively.

\section{Hedgehog signaling pathway}

Activation of Hedgehog signaling induces hepatic

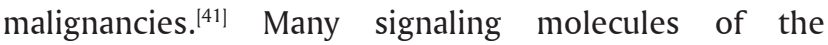
Hedgehog pathway, Sonic Hedgehog, PTC, SMO and GLl-1, are over expressed in HB. Specific blockade of Hedgehog signal transduction inhibits the growth of HB. ${ }^{[42]}$

\section{ANTI-TUMOR PROPERTIES OF CURCUMIN IN LIVER CANCER}

As an anti-tumor agent, curcumin has been reported to exhibit direct action by inhibiting proliferation of tumor cells as well as an indirect action by inhibiting angiogenesis [Figure1].

\section{Curcumin stimulates apoptosis of cancer cells}

Apoptosis or programmed cell death can be triggered by extrinsic and intrinsic pathways. ${ }^{[43]}$ Intrinsic pathway is stimulated by internal stimuli such as DNA abnormality, hypoxia, viral infection, cellular distress, etc. Extrinsic (receptor mediated) pathway is initiated by extracellular messenger proteins such as TNF. Intrinsic pathway is regulated by the members of the $\mathrm{Bcl}-2$ family of proteins, which can be divided into three groups: (1) pro-apoptotic members that promote apoptosis, e.g. Bax, Bak; (2) antiapoptotic members that protect cell from apoptosis, e.g. Bcl-2, Bcl-w; (3) BH-3, only protein that promote apoptosis through indirect mechanism. Extrinsic pathway of apoptosis is mediated by several caspases which are proteases with specific cellular targets, caspase- 8 followed by caspase 3, 6 and 7. Cancer cells are resistant to apoptosis and this leads to their uncontrolled growth.

Curcumin affects the following pathways and promotes apoptosis of cancer cells.

EF24 is a synthetic compound and a potent curcumin analogue with enhanced bioavailability. Liu et al. ${ }^{[44]}$ demonstrated that EF24 significantly suppressed HCC and induced apoptosis in mouse liver cancer cell line. The levels of cytochrome c, cleaved-PARP, Bax and activated caspase- 3 were increased whereas the levels of PARP and $\mathrm{Bcl}-2$ were down-regulated as compared to control (nonEF24 treated) groups. Incubation of human hepatoma SMMC-7721 cells with curcumin for $24 \mathrm{~h}$ resulted in decreased expression of bcl-2 protein whereas expression of bax protein increased significantly and a higher curcumin concentration showed potent cytotoxicity. ${ }^{[45]}$

EF24 induces cell cycle arrest at G2/M phase in mouse liver cancer cells. Passage from G2 to M-phase requires the activation of $\mathrm{cdc} 2$ by cyclin $\mathrm{B} 1$. With the use of curcumin, the levels of cyclin B1 and cdc2 in the cells 
were significantly reduced..$^{[44]}$ Wang et al..$^{[46]}$ showed that treatment with curcumin resulted in the activation of Chk1 mediated G2 checkpoint which caused the induction of G2/M arrest and resistance of cancerous cells to curcumininduced apoptosis. In hepatoma cell lines Chk1-mediated activation of G2 checkpoint was required for curcumin induced G2/M arrest. Chk1 inhibition reversed this arrest significantly and sensitizes curcumin resistant cells to apoptosis. Single knockdown of Chk1 in Hep3B cells caused the abrogation of curcumin-induced G2/M arrest and decreased phosphorylation of Cdk1. Thus G2/M arrest is Chk1-mediated and may be responsible for the resistance of cancer cells to curcumin-induced apoptosis. ${ }^{[46]}$

Caspase-3 is the key member of caspase family proteins that are crucial in apoptosis. The pro-apoptotic effect of curcumin was assessed by measurement of caspase- 3 activity. Dai et al. ${ }^{[47]}$ demonstrated that curcumin significantly elevated the activity of caspase-3.

Tumor necrosis factor-related apoptosis inducing ligand (TRAIL) can induce apoptosis in cancer cells by binding to four types of membrane bound death receptors (DR4, DR5, DcR1 and DcR2). Jung et al. ${ }^{|48|}$ established that curcumin sensitizes human renal cancer cells to TRAIL mediated apoptosis. Membrane bound death receptors DR4 and DR5 have a conserved cytoplasmic region called the death domain which is necessary for TRAIL-induced apoptosis. ${ }^{[4]]}$ TRAIL induces apoptosis only in the cancer cells without any toxicity to normal cells because normal cells have decoy receptors on their surface. ${ }^{[49]}$

Notch signaling can either behave as an oncogene or as a tumor suppressor. When the pathway is unregulated, it behaves as an oncogene and hence it results in increased cell proliferation, prevention of differentiation and inhibition of apoptosis. ${ }^{[50]}$ Aziz et al. ${ }^{[51]}$ proved that curcumin has inhibitory effects on Notch1 signaling and its target genes (Hes1 and cyclin D1).

\section{Cytotoxic/anti-proliferation activity of curcumin}

Curcumin has been demonstrated to inhibit the proliferation of HepG2 cells (Hepatoma cell line) in a dose and time dependent manner in in vitro studies. ${ }^{[47]}$ Curcumin demonstrates anti-proliferative action by blocking two important pathways; the Wnt signaling pathway and the Hedgehog pathway. Both these pathways affect the cancer stem cells.

\section{Blockade of the Wnt signaling pathway}

Wnt signaling pathways have important role in carcinogenesis as well as embryonic development. Wnt proteins can activate different pathways but canonical wnt $/ \beta$-catenin pathway is the most studied. In the absence of wnt proteins, $\beta$-catenin is targeted to the destruction complex for its phosphorylation at specific sites, $\beta$-catenin accumulates and recruited to the nucleus by Bcl- 9 adaptor proteins. In the nucleus, $\beta$-catenin binds to the T-cell factor/ lymphocyte enhancer factor, transcription factors and activates the expression of target genes like c-myc, VEGF, cyclin -D1, that results in cell proliferation. ${ }^{[52]}$ Curcumin has been shown to interrupt this pathway and thus suppress the expression of $\beta$-catenin target genes like c-myc, VEGF, cyclin-D. Curcumin has been reported to suppress cell proliferation and induced apoptosis by interrupting wnt signaling via decreasing $\beta$-catenin activity. ${ }^{[53]}$ Curcumin and its reduced analogue tetrahydrocurcumin showed anti-proliferative effects on HepG2 cell lines. ${ }^{[54]}$ HepG2 cells (hepatoma cell line) when treated with novel curcumin derivative and mesenchymal stem cells showed a significantly decrease of proliferation rate as compared to the control group..$^{[51]} \mathrm{Xu}$ et al. ${ }^{[53]}$ found that curcumin significantly suppressed the cell proliferation, decreased the $\beta$-catenin accumulation and induced apoptosis in human HCC cell lines BEL-7402 and QGY-7703 in a dose dependent manner. A dose dependent decrease in the expressions of c-myc and VEGF was also reported. Thus curcumin attenuated wnt signals in HCC cells.

\section{Blockade of the Hedgehog pathway}

The Hedgehog pathway is another potential target for cancer stem cell eradication. In liver cells, the suppression of the Sonic Hedgehog pathway by small interfering RNA decreased HCC cell proliferation also chemosensitized the cells to 5-fluorouracil and induction of cell apoptosis. ${ }^{\text {[5] }}$ In $\mathrm{HB}$, blocking the $\mathrm{Hh}$ Hedgehog signaling pathway with an antagonist cyclopamine strongly inhibited cell proliferation of HB cell lines. ${ }^{[56]}$ A significant decrease in expression of Notch1, Hes1 and cyclin D1 was observed in HepG2 cells upon treatment of hepatoma cell lines (HepG2) with mesenchymal stem cells conditioned medium (MSCs $\mathrm{CM}$ ) and novel curcumin derivative (NCD). ${ }^{[51]}$ Pre-treatment of MSCs with NCD resulted in a more significant decrease in the expression of these genes. Thus NCD and MSCs had synergistic effect in suppression of Notch1 signaling. ${ }^{[51]}$

\section{Induce differentiation of cancer stem cell}

Cancer stem cells comprising a small proportion of cancer cells sustain tumor growth and are more resistant to conventional chemotherapy than other more differentiated cancer cells. Malignancy may thus be treated by inducing the differentiation of cancer stem cells and thus making them lose their self-renewal property. Curcumin has been shown to induce differentiation of embryonic stem cells through possible modulation of nitric oxide-cyclic GMP pathway. ${ }^{[57]}$

\section{Anti-antiangiogenic effects of curcumin}

Active neovascularisation is a predominant feature in HCC and supports tumor growth. Angiogenesis starts when tumor cells start sending signals to the nearby surrounding normal host tissue and encourage the release of signaling molecules that initiate and promote angiogenesis. This angiogenesis provides the tumor cells with oxygen and 
nutrients and also a route to enter general circulation. HCC cells secrete various angiogenesis activators like VEGF, platelet derived growth factor, TGF- $\beta$. Among these, VEGF is most critical antigenic factor. ${ }^{[3]}$ Cancer cells grow in hypoxic conditions that lead to expression of several hypoxia response genes which are involved in metabolic dysregulation. ${ }^{[58]}$ These include inflammatory angiogenic molecules secreted by tumor cells like cyclooxygenase- 2 (COX-2) and inducible nitric oxide synthase. Angiogenesis requires the expressions of COX-2, VEGF and matrix metalloproteinase-9 (MMP-9). Anti angiogenic effects of curcumin have been demonstrated. ${ }^{[54]}$ COX-2 and VEGF are associated with angiogenesis in HCC. ${ }^{[59]}$ ROS generated as a result of oxidative stress in the cells also causes up regulation of MMPs that causes angiogenesis and invasiveness. ${ }^{[60 \mid}$ Cao et al..$^{[61]}$ found that curcumin treatment inhibited the cell proliferation and induce apoptosis in cancer cells. Curcumin also exhibited inhibitory action on cancer metastasis by inhibiting the secretion of MMP-9. ${ }^{\text {[62] }}$

Vasculogenic mimicry (VM) refers to the functional plasticity of the aggressive and metastatic tumor cells forming the non-endothelial tumor cell-lined microvascular channels which contribute to the tumor progression. VM is detected in gliomas. ${ }^{[63]}$ Liang et al. ${ }^{[64]}$ demonstrated that curcumin inhibits vasculogenic mimicry through down regulation of protein and mRNA expression of erythropoietin producing hepatocellular carcinoma-A2, phosphoinositide 3-kinase and MMP-2. The same authors reported that curcumin was found to inhibit the VM formation of glioma U251 cells which they were unable to form network structures, inhibit the migration and invasion in a dose dependent manner and reduced the mRNA expression of EphA2, PI3K and MMP-2 as detected by quantitative polymerase chain reaction $(\mathrm{QPCR})$.

\section{Prevents metastasis and tumor progression \\ TNF- $\alpha$ inhibition}

TNF- $\alpha$ has a very important role in tumor cell survival and metastasis. Curcumin inhibits TNF- $\alpha$ expression. However, the hydrophobicity and low bioavailability of curcumin are the major barriers. Thus, scientists have encapsulated curcumin in microcells to make it a sustained release preparation in order to increase its solubility and bioavailability. ${ }^{[65]}$ Moreover curcumin bearing microcells significantly reduced the levels of the liver enzymes in HCC induced animal group as compared to the free form curcumin. In addition, curcumin bearing microcells induced expression of proapoptotic molecules like p53 and Bax.

\section{DNA damage induced by curcumin}

Mitochondrial DNA (mDNA), being in closer contact to ROS produced in mitochondria, is more prone to oxidative damage. Cao et al. ${ }^{[66]}$ reported mitochondrial and nuclear DNA damage induced by curcumin in human hepatoma (HepG2) cells, a cell line that retains many characteristics of hepatocytes. Furthermore, QPCR assay revealed that curcumin led to dose dependent damage in nuclear as well as mitochondrial genomes.

\section{EPCAM as a target in cancer therapy}

EpCAM is potentially a promising target as it is highly expressed in most cancer cells as well as on cancer stem cells. In normal tissue, EpCAM is localized to basolateral membranes. Thus, the ease of access for EpCAM-binding antibodies is lower for normal cells than for cancer cells. EpCAM is strongly over expressed in cancer cells and thus might be partly unbound and more accessible for targeting antibodies and curcumin-loaded lipid-polymer-lecithin hybrid nanoparticles have been used against EPCAM for targeted delivery to colorectal adenocarcinoma cells. ${ }^{[67]}$

\section{ROLE OF CURCUMIN IN DECREASING ADVERSE EFFECTS OF CHEMOTHERAPY}

\section{Neuroprotective effect of curcumin}

Cisplatin is potent chemotherapeutic agent with adverse effects like nephrotoxicity and peripheral neuropathy. Mendonca et al. ${ }^{[68]}$ reported the neuroprotective effect of curcumin against cisplatin induced cytotoxicity without any interference of curcumin with the cytotoxic activity of cisplatin.

\section{Anti-inflammatory action}

Curcumin has proven anti-inflammatory, antioxidant, antimicrobial, hepatoprotective, immunostimulant, antiseptic, and antimutagenic properties. ${ }^{[69]}$ This antiinflammatory action of turmeric helps to decrease the side effects like gastro intestinal inflammation due to chemotherapy or radiotherapy.

\section{Anti-infective action}

Patients who receive chemotherapy are immunocompromised and prone to multiple infections. Curcumin with its beneficial anti-infective action would help to prevent infections and take care of minor infections. ${ }^{\text {[70-72] }}$

\section{ROLE OF CURCUMIN IN WOUND HEALING}

After liver resection of the tumor, liver regeneration takes place. Patients with cancer have poor nutrition and poor healing following chemotherapy. The catabolic phase following surgery is enhanced and hence healing takes a long time. Curcumin would be beneficial to expedite the liver regeneration. ${ }^{.73]}$

\section{POTENTIAL SIDE EFFECTS OF CURCUMIN}

Curcumin is generally considered safe and has been used since ages in Asian countries as a condiment. The low incidence of colorectal carcinoma in India has been linked to the consumption of curcumin in all meals. There have been no side effects in the daily consumption in cooked food. However, when consumed raw in larger doses, it may 
cause gastric irritation, stomach upset, nausea, diarrhoea, allergic skin reaction, and antithrombosis activity. The Food and drug administration has declared curcumin as: generally regarded as safe. ${ }^{[70]}$ Curcumin exhibits both antioxidant and prooxidant activities. ${ }^{\text {[3] }}$ These opposing actions of curcumin might be regulated by its concentration that might switch roles. Thus research studies are needed to study the effects of curcumin in different conditions and the doses need to be titrated to get the maximum benefit. Till date, there have not been any long-term studies with curcumin, which show its toxic or adverse effects. Such studies are necessary in both animal models and human subjects to determine the long term safety of curcumin. Currently, there are no carcinogenic effects of consuming curcumin in doses of around 100-200 mg/day over long periods of time..$^{\mid 70]}$

\section{CONCLUSION}

Liver cancer is a leading cause of death in children and adults. The treatment revolves around chemotherapy, radiotherapy and surgery. Recent advances include transcatheter arterial chemoembolization, radioembolization, anti-angioigenic drugs like sorafenib and liver transplantation in advanced stages. Despite improving diagnostic methods, the results have been far from satisfactory mainly due to advanced stage at diagnosis and the side effects of chemotherapy. However, the successful cure of liver cancer mandates destruction of both the differentiated neoplastic cells and the potential cancer stem cells. The conventional anticancer therapies reduce the tumor mass, but potentially leave behind cancer-initiating cells. Thus, new combinations of therapies may be needed to overcome the complex network of signaling pathways, and ultimately inhibit the signaling that controls tumor growth and survival. Adjuvant curcumin along with the current modalities of treatment may help to overcome the side effects and also have synergistic action as an anti-cancer agent.

Curcumin has been reported to inhibit telomerase activity in human cancer cell lines. ${ }^{[74]}$ Synergistic anti-cancer effects of curcumin has also been demonstrated in conjunction with chemotherapeutic drugs such as doxorubicin and paclitaxel by in vivo animal models, and with cisplatin, 5 -FU, and adriamycin by in vitro studies. ${ }^{\text {[75-79] }}$

Synergistic effects of curcumin have also been demonstrated in combined treatment with anti-angiogenic agents such as leflunomide and perindopril in in vivo mice models. ${ }^{[80]}$

Thus, to conclude, curcumin has a lot of potential to act as an adjuvant remedy in liver cancer. As far as toxicity issue is concerned, herbal medicines are much safer, have less adverse effects and relatively cheaper than conventional medicines. Curcumin as an adjunct would have a synergistic anti-cancer action and would also protect against the side effects of the current chemotherapeutic agents. Previous studies have also claimed its antitumor effects against various types of cancers due to its inhibitory effects on many types of pathways. In this article we have discussed various pharmacological activities of curcumin along with its various antitumor mechanisms.

As we have discussed, oxidative stress is a risk factor cancer. Curcumin, being a strong antioxidant has been proved to scavenge reactive species and can control tumor cell proliferation. Although preclinical results are promising but its clinical use in the treatment of HCC and $\mathrm{HB}$ remains to be elucidated.

Curcumin has the ability to modify many signaling pathways demonstrating its anti-tumor potential. Also, we noticed that curcumin has been proved to possess strong anti-oxidant and anti-inflammatory properties. Curcumin also targets principal anti-antigenic molecules like VEGF and COX-2. All these properties of curcumin are essential for its use as a therapeutic anti-tumor agent. It provides a future perspective for the development of a novel adjuvant anticancer agent for humans.

Poor bioavailability and hydrophobicity of curcumin are the main obstacles in its path to be used clinically as an anti-tumor agent. However this issue can be resolved with the advancements in the drug delivery like formation of nanoparticles and microcells of curcumin via polymerization and these can be used to target cancerous cells without affecting other normal cells. Thus we can conclude that curcumin might be a promising candidate as an adjuvant therapy for liver cancer in the future but further research is needed to elucidate its various mechanisms of action, to reveal its therapeutic strategy and to titrate the dose required to reap maximum benefit.

\section{Financial support and sponsorship}

Nil.

\section{Conflicts of interest}

There are no conflicts of interest.

\section{REFERENCES}

1. Litten JB, Tomlinson GE. Liver tumors in children. Oncologist 2008; 13:812-20.

2. Darvesh AS, Aggarwal BB, Bishayee A. Curcumin and liver cancer: a review. Curr Pharm Biotechnol 2012;13:218-28.

3. Chintana P. Role of curcumin on tumor angiogenesis in hepatocellular carcinoma. Naresuan Univ J 2008;16:239-54.

4. Lee EO, Lee HJ, Hwang HS, Ahn KS, Chae C, Kang KS, Lu J, Kim $\mathrm{SH}$. Potent inhibition of Lewis lung cancer growth by heyneanol A from the roots from the Vitis amurensis through apoptotic and antiantigenic activities. Carcinogenesis 2006;27:2059-69.

5. Khan N, Afaq F, Mukhtar H. Cancer chemoprevention through dietary antioxidants: progress and promise. Antioxid Redox Signal 2008; 10:475-510.

6. Yang CS, Landau JM, Huang MT, Newmark HL. Inhibition of 
carcinogenesis by dietary polyphenolic compounds. Ann Rev Nutr 2001;21:381-406.

7. Mann CD, Neal CP, Garcea G, Manson MM, Dennison AR, Berry DP. Phytochemicals as potential chemopreventive and chemotherapeutic agents in hepatocarcinogenesis. Eur J Cancer Prev 2009; 18:13-25.

8. Jacob A, Wu R, Zhou M, Wnag P. Mechanism of anti-inflammatory effect of curcumin: PPAR-gamma activation. PPAR Res 2007;2007:15 .

9. Sandhur SK, Ichikawa H, Pandey MK, Kunnumakkara AB, Sung B, Sethi G, Kunnumakkara AB, Aggarwal BB. Role of pro-oxidants and antioxidants in the anti-inflammatory and apoptotic effects of curcumin (diferuloylmethane). Free Radic Biol Med 2007;43:56880 .

10. Kunnumakkara AB, Anand P, Aggarwal BB. Curcumin inhibits proliferation, invasion, angiogenesis and metastasis of different cancers through interaction with multiple cell signaling proteins. Cancer Lett 2008;269:199-225.

11. Ricky AS, Stephanie AE, Sharon LP. Phase I clinical trial of ora curcumin: biomarkers of systemic activity and compliance. Clin Cancer Res 2004;10:6847-54.

12. Suryanarayana P, Satyanarayana A, Balakrishna N, Kumar PU, Reddy GB. Effect of turmeric and curcumin on oxidative stress and antioxidant enzymes in streptozotocin-induced diabetic rat. $\mathrm{Med} \mathrm{Sci}$ Monit 2007;13:BR286-92.

13. Sreejayan, Rao MN. Curcuminoids as potent inhibitors of lipid peroxidation. J Pharm Pharmacol 1994;46:1013-6.

14. Michalopoulos GK. Liver regeneration. J Cell Physiol 2007;213:286300 .

15. Alison MR. Liver stem cells: implications for hepatocarcinogenesis. Stem Cell Rev 2005;1:253-60.

16. Katoh M. WNT signaling pathway and stem cell signaling network. Clin Cancer Res 2007;13:4042-5.

17. Oishi N, Wang XW. Novel therapeutic strategies for targeting liver cancer stem cells. Int J Biol Sci 2011;7:517-35.

18. Trzpis M, McLaughlin PM, de Leij LM, Harmsen MC. Epithelia cell adhesion molecule: more than a carcinoma marker and adhesion molecule. Am J Pathol 2007;171:386-95.

19. Yamashita T, Budhu A, Forgues M, Wang XW. Activation of hepatic stem cell marker EpCAM by Wnt-beta-catenin signaling in hepatocellular carcinoma. Cancer Res 2007;67:10831-9.

20. Reya T, Clevers H. Wnt signaling in stem cells and cancer. Nature 2005;434:843-50.

21. Ishizaki Y, Ikeda S, Fujimori M, Shimizu Y, Kurihara T, Itamoto T, Kikuchi A, Okajima M, Asahara T. Immunohistochemical analysis and mutational analyses of beta-catenin, Axin family and APC genes in hepatocellular carcinomas. Int J Oncol 2004;24:1077-83.

22. Yong KJ, Chai L, Tenen DG. Oncofetal gene SALL4 in aggressive hepatocellular carcinoma. N Engl J Med 2013;369:1171-2.

23. Zeng SS, Yamashita T, Kondo M, Nio K, Hayashi T, Hara Y Nomura Y, Yoshida M, Hayashi T, Oishi N, Ikeda H, Honda M, Kaneko S. The transcription factor SALL4 regulates stemness of EpCAM-positive hepatocellular carcinoma. J Hepatol 2014;60:127-34.

24. Tang Y, Kitisin K, Jogunoori W, Li C, Deng CX, Mueller SC, Ressom HW, Rashid A, He AR, Mendelson JS, Jessup JM, Shetty K, Zasloff M, Mishra B, Reddy EP, Johnson L, Mishra L. Progenitor/stem cells give rise to liver cancer due to aberrant TGF-beta and IL-6 signaling. Proc Natl Acad Sci USA 2008;105:2445-50.

25. Yuan F, Zhou W, Zou C, Zhang Z, Hu H, Dai Z, Zhang Y. Expression of Oct4 in HCC and modulation to wnt $/ \beta$-catenin and TGF- $\beta$ signal pathways. Mol Cell Biochem 2010;343:155-62.

26. Weng AP, Aster JC. Multiple niches for Notch in cancer: context is everything. Curr Opin Genet Dev 2004;14:48-54.

27. Androutsellis-Theotokis A, Leker RR, Soldner F, Hoeppner DJ, Ravin R, Poser SW, Rueger MA, Bae SK, Kittappa R, McKay RD. Notch signaling regulates stem cell numbers in vitro and in vivo. Nature 2006;442:823-6.

28. Villavicencio EH, Walterhouse DO, Iannaccone PM. The sonic hedgehog-patched-gli pathway in human development and disease. Am J Hum Genet 2000;67:1047-54
29. Chen W, Kozielski R, LeVea C, Chen F. The advances in molecular biology of hepatoblastoma: implications for diagnostic pathology. $N$ A J Med Sci 2012;5:217-23.

30. Adesina AM, Lopez-Terrada D, Wong KK, Gunaratne P, Nguyen Y, Pulliam J, Margolin J, Finegold MJ. Gene expression profiling reveals signatures characterizing histologic subtypes of hepatoblastoma and global deregulation in cell growth and survival pathways. Hum Pathol 2009;40:843-53.

31. Cairo S, Armengol C, Buendia MA. Activation of Wnt and Myc signaling in hepatoblastoma. Front Biosci (Elite Ed) 2012;4:480-6.

32. Spiegelman VS, Slaga TJ, Pagano M, Minamoto T, Ronai Z, Fuchs SY. Wnt/beta-catenin signaling induces the expression and activity of betaTrCP ubiquitin ligase receptor. Mol Cell 2000;5:877-82.

33. López-Terrada D, Gunaratne PH, Adesina AM, Pulliam J, Hoang DM, Nguyen Y, Mistretta TA, Margolin J, Finegold MJ. Histologic subtypes of hepatoblastoma are characterized by differential canonical Wnt and Notch pathway activation in DLK + precursors. Hum Pathol 2009;40:783-94.

34. Ranganathan S, Tan X, Monga SP. Beta-catenin and met deregulation in childhood hepatoblastomas. Pediatr Dev Pathol 2005;8:435-47.

35. Park WS, Oh RR, Park JY, Kim PJ, Shin MS, Lee JH, Kim HS, Lee SH, Kim SY, Park YG, An WG, Kim HS, Jang JJ, Yoo NJ, Lee JY. Nuclear localization of beta-catenin is an important prognostic factor in hepatoblastoma. J Pathol 2001;193:483-90.

36. Krawczuk-Rybak M, Jakubiuk-Tomaszuk A, Skiba E, Plawski A. Hepatoblastoma as a result of APC gene mutation. J Pediatr Gastroenterol Nutr 2012;55:334-6.

37. Ueda Y, Hiyama E, Kamimatsuse A, Kamei N, Ogura K, Sueda T. Wnt signaling and telomerase activation of hepatoblastoma: correlation with chemosensitivity and surgical resectability. J Pediatr Surg 2011;46:2221-7.

38. Armengol C, Cairo S, Fabre M, Buendia MA. Wnt signaling and hepatocarcinogenesis: the hepatoblastoma model. Int J Biochem Cell Biol 2011;43:265-70.

39. Purcell R, Childs M, Maibach R, Miles C, Turner C, Zimmermann A , Sullivan M. HGF/c-Met related activation of $\beta$-catenin in hepatoblastoma. J Exp Clin Cancer Res 2011;30:96.

40. Litten JB, Chen TT, Schultz R, Herman K, Comstock J, Tomlinson GE, Rakheja D. Activated NOTCH2 is overexpressed in hepatoblastomas: an immunohistochemical study. Pediatr Dev Pathol 2011;14:378-83.

41. Sicklick JK, Li YX, Jayaraman A, Kannangai R, Qi Y, Vivekanandan P, Ludlow JW, Owzar K, Chen W, Torbenson MS, Diehl AM. Dysregulation of the Hedgehog pathway in human hepatocarcinogenesis. Carcinogenesis 2006;27:748-57.

42. Eichenmüller M, Gruner I, Hagl B, Haberle B, Muller-Hocker J, von Schweinitz D, Kappler R. Blocking the hedgehog pathway inhibits hepatoblastoma growth. Hepatology 2009;49:482-90.

43. Ziegler DS, Kung AL. Therapeutic targeting of apoptosis pathways in cancer. Curr Opin Oncol 2008;20:97-103.

44. Liu H, Liang Y, Wang L, Tian L, Song R, Han T, Pan S, Liu L. In vivo and in vitro suppression of hepatocellular carcinoma by EF24, a curcumin analog. PLoS One 2012;7:e48075.

45. Yu J, Zhou X, He X, Dai M, Zhang Q. Curcumin induces apoptosis involving bax/bcl-2 in human hepatoma SMMC-7721 cells. Asian Pac J Cancer Prev 2011;12:1925-9.

46. Wang WZ, Cheng J, Luo J, Zhuang SM. Abrogation of G2/M arrest sensitizes curcumin-resistant hepatoma cells to apoptosis. FEBS Lett 2008;582:2689-95.

47. Dai X, Yin H, Sun L, Hu X, Zhou C, Zhou Y Zhang W, Huang XE, Li $\mathrm{XC}$. Potential therapeutic efficacy of curcumin in liver cancer. Asian Pac J Cancer Prev 2013;14:3855-9.

48. Jung EM, Lim JH, Lee TJ, Park JW, Choi KS, Kwon TK. Curcumin sensitizes tumor necrosis factor-related apoptosis-inducing ligand (TRAIL)-induced apoptosis through reactive oxygen speciesmediated upregulation of death receptor 5 (DR5). Carcinogenesis 2005;26:1905-13

49. Ashkenzi A, Dixit VM. Apoptosis control by death and decoy receptors. Curr Opin Cell Biol 1999;11:255-60.

50. Yin L, Velazquez OC, Liu ZJ. Notch signaling emerging molecular 
targets for cancer therapy. Biochem Pharmacol 2010;80:690-701.

51. Aziz MTA, Khaled HM, Hindawi AE, Roshdy NK, Rashed LA, Sabry D, Hassouna AA, Taha F, Ali WI. Effect of mesenchymal stem cells and novel curcumin derivative on Notch1 signaling in hepatoma cell line. Biomed Res Int 2013;2013:e129629.

52. Rao TP, Kuhl M. An updated overview on Wnt signaling pathways: a prelude for more. Circ Res 2010;106:1798-806.

53. Xu MX, Zhao L, Deng C, Yang L, Wang Y, Guo T, Li L, Lin J, Zhang L. Curcumin suppresses proliferation and induces apoptosis of human hepatocellular carcinoma cells via the wnt signaling pathway. Int J Oncol 2013;43:1951-9.

54. Yoysungnoen P, Wirachwong P, Changtam C, Suksamrarn A, Patumraj S. Anti-cancer and anti-antigenic effects of curcumin and tetrahydrocurcumin on implanted hepatocellular carcinoma in nude mice. World J Gastroenterol 2008;14:2003-9.

55. Aza-Blanc P, Kornberg TB. Ci: a complex transducer of the hedgehog signal. Trends Genet 1999;15:458-62.

56. Sicklick JK, Li YX, Jayaraman A, Kannangai R, Qi Y, Vivekanandan P, Ludlow JW, Owzar K, Chen W, Torbenson MS, Diehl AM. Dysregulation of the Hedgehog pathway in human hepatocarcinogenesis. Carcinogenesis 2006;27:748-57.

57. Mujoo K, Nikonoff LE, Sharin VG, Bryan NS, Kots AY, Murad F. Curcumin induces differentiation of embryonic stem cells through possible modulation of nitric oxide-cyclic GMP pathway. Protein Cell 2012;3:535-44

58. Fox SB, Gasparini G, Harris AL. Angiogenesis: Pathological, prognostic and growth factor pathways and their link to trial design and anticancer drugs. Lancet Oncol 2001;2:278-89.

59. Cheng AS, Chan HL, To KF, Leung WK, Chan KK, Liew CT, Sung JJ. Cyclooxigenase-2 pathway correlates with vascular endothelial growth factor expression and tumor angiogenesis in hepatitis-B virus-associated hepatocellular carcinoma. Int J Oncol 2004;24:85360.

60. Reuter S, Gupta SC, Chaturvedi MM, Aggarwal BB. Oxidative stress, inflammation and cancer: how are they linked? Free Radic Biol Med 2010;49:1603-16.

61. Cao J, Liu Y, Jia L, Zhou HM, Kong Y, Ynag G, Jiang LP, Li QJ, Zhong LF. Curcumin induces apoptosis through mitochondrial hyperpolarization and mtDNA damage in human hepatoma G2 cells. Free Radic Boil Med 2007;43:968-75.

62. Aggarwal BB, Bhatt ID, Ichikawa H, Ahn KS, Sethi G, Sandur SK, Sundaram C, Seeram N, Shishodia S. Curcumin-biological and medicinal properties. New York, USA: CRC press; 2007.

63. Liu XM, Zhang QP, Mu YG, Zhang XH, Sai K, Pang JCS, Ng HK, Chen ZP. Clinical significance of vasculogenic mimicry in human gliomas. J Neurooncol 2011;105:173-9.

64. Liang Y, Huang M, Li J, Sun X, Jiang X, Li L, Ke Y. Curcumin inhibits vasculogenic mimicry through the downregulation of erythropoietinproducing hepatocellular carcinoma-A2, phosphoinositide 3-kinase and matrix metalloproteinase-2. Oncol Lett 2014;8:1849-55.

65. Farazuddin M, Dua B, Zia Q, Khan AA, Joshi B, Owais M. Chemotherapeutic potential of curcumin bearing microcells against hepatocellular carcinoma in model animals. Int $J$ Nanomedicine 2014;9:1139-52

66. Cao J, Jia L, Zhou HM, Liu Y, Zhong LF. Mitochondrial and nuclear
DNA damage induced by curcumin in human hepatoma G2 cells. Toxicol Sci 2006;91:476-83.

67. Li L, Xiang D, Shigdar S, Yang W, Li Q, Lin J, Liu K, Duan W. Epithelial cell adhesion molecule aptamer functionalized PLGAlecithin-curcumin-PEG nanoparticles for targeted drug delivery to human colorectal adenocarcinoma cells. Int J Nanomed 2014;9:108396.

68. Mendonca LM, da Silva MC, Teixeira CC, de Freitas LA, Bianchi ML, Antunes LM. Curcumin reduces cisplatin-induced neurotoxicity in NGF-differentiated PC12 cells. Neurotoxicol 2013;34:205-11.

69. Julie SJ. Anti-inflammatory properties of curcumin, a major constituent of curcuma longa: a review of preclinical and clinical research. Altern Med Rev 2009;1:141-53.

70. Aggarwal BB, Harikumar KB. Potential therapeutic effects of curcumin, the anti-inflammatory agent, against neurodegenerative, cardiovascular, pulmonary, metabolic, autoimmune and neoplastic diseases. Int J Biochem Cell Biol 2009;41:40-59.

71. Nagpal M, Sood S. Role of curcumin in systemic and oral health: an overview. J Nat Sci Biol Med 2013;4:3-7.

72. Sandur SK, Ichikawa H, Pandey MK, Kunnumakkara AB, Sung B, Sethi G, Aggarwal BB. Role of prooxidants and antioxidants in the anti-inflammatory and apoptotic effects of curcumin (diferuloylmethane). Free Radic Biol Med 2007;43:568-80.

73. Toydemir T, Kanter M, Erboga M, Oquz S, Erenoglu C. Antioxidative, antiapoptotic, and proliferative effect of curcumin on liver regeneration after partial hepatectomy in rats. Toxicol Ind Health 2015;31:162-72.

74. Cui S, Qu X, Xie Y, Zhou L, Nakata M, Makuuchi M, Tang W. Curcumin inhibits telomerase activity in human cancer cell lines. Int $J$ Mol Med 2006;18:227-31.

75. Zhao X, Chen Q, Liu W, Li Y, Tang H, Liu X, Yang X. Codelivery of doxorubicin and curcumin with lipid nanoparticles results in improved efficacy of chemotherapy in liver cancer. Int $J$ Nanomedicine 2014;10:257-70.

76. Ganta S, Devalapally H, Amiji M. Curcumin enhances oral bioavailability and anti-tumor therapeutic efficacy of paclitaxel upon administration in nanoemulsion formulation. $J$ Pharm Sci 2010;99:4630-41.

77. Notarbartolo M, Poma P, Perri D, Dusonchet L, Cervello M, D'Alessandro N. Antitumor effects of curcumin, alone or in combination with cisplatin or doxorubicin, on human hepatic cancer cells. Analysis of their possible relationship to changes in NF-kB activation levels and in IAP gene expression. Cancer Lett 2005;224:53-5

78. Zhu R, Wu X, Xiao Y, Gao B, Xie Q, Liu H, Wang S. Synergetic effect of SLN-curcumin and LDH-5-Fu on SMMC-7721 liver cancer cell line. Cancer Biother Radiopharm 2013;28:579-87.

79. Qian H, Yang Y, Wang X. Curcumin enhanced adriamycin-induced human liver-derived hepatoma G2 cell death through activation of mitochondria-mediated apoptosis and autophagy. Eur J Pharm Sci 2011;43:125-31.

80. Nasr M, Selima E, Hamed O, Kazem A. Targeting different antigenic pathways with combination of curcumin, leflunomide and perindopril inhibits diethylnitrosamine-induced hepatocellular carcinoma in mice. Eur J Pharmacol 2014;723:267-75. 